\title{
Editorial: Interventions into soil can amelliorate its properties
}

Dimitrios Kolymbas

em. Univ.-Prof. Dr. Unit of Geotechnical Engineering, Techniker Strasse 13,

Universität Innsbruck (dimitrios.kolymbas@uibk.ac.at)

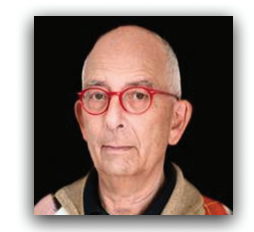

Soil, the principal constituent of our underground, is a product of erosion and originates from rock. The principal agents of erosion, water and wind, have ensured that the soil was sorted according to its grain size. In this way the two main groups of materials soil mechanics deals with: sand and clay. For decade, the science of soil mechanics has been investigating the mechanical behaviour of sand and clay, and considerable progress has been achieved both in experimental investigation and mathematical description of the soil behaviour. However, as is often the case, marginalised groups exhibit deviant behaviour, the recording of which presents particular difficulties. One example of atypical soil is the debris, created either by the sudden collapse of rock in the case of rockfalls and landslides or by the intended demolition of buildings consisting of concrete or bricks. Debris is characterised by the absence of sorting depending on grain size and, consequently, by the presence of large 'grains' or blocks that can hardly be investigated with the standard laboratory apparatuses of soil mechanics; neither can it be easily compacted. Therefore it constitutes a material which is not readily used neither for the construction of dams and fills, nor as building ground. Of course, you can work with almost any material if you only know its properties exactly. But unfortunately that is not the case for the aforementioned debris. One would think that the current state of science would allow us to deduce the mechanical properties of a granulate from the shape and strength of each individual grain. Unfortunately, this is not yet the case. We are still a long way from understanding the extremely complicated mechanical behaviour of granular materials. Stress- and deformation-dependent stiffness, dilatancy, contractancy and critical states are very difficult to accommodate in a theoretical model. Especially since soil mechanics had obviously taken the wrong path following the plasticity theory. Only recently has a promising new theoretical concept been proposed, the theory of barodesy, derived from the asymptotic behaviour of soils (Kolymbas, 2021). However, it can't yet be applied to debris due to a lack of experimental results. Studying the asymptotic properties of a material means to analyse its memory. In this respect, the principle of fading memory is a general statement of major significance.

Engineers, however, have to solve urgent problems-even if the theoretical foundations are still a long way off. It is therefore to be welcomed if scientific studies are presented in this regard. It is indeed possible to consolidate debris with cement or to use it to stiffen a soft soil. Two articles in this issue deal with this, Chen et al. (2021) and Alnunu and Nalbantoglu (2021). One can also try to treat debris with suitable additives in such a way that its mechanical properties and/or its environmental compatibility are improved. This is the subject of Inazumi et al. (2021) work.

However, debris is not the only problematic soil type. There are also many other problem soils, such as those that exhibit excessive volume fluctuations due to swelling and shrinkage. One article in this issue deals with how to reduce the volume fluctuations of such soils with suitable additives and with special loading (Miao et al., 2021).

An often overlooked mechanical effect on soil comes from the percolation with water. Natural slopes or embankments are particularly at risk, as landslides can easily occur. Such landslides can be caused by the downhill driving force of infiltrated water, for example from precipitation. In this context, recording the effect of the percolating water is not as problematic as answering the question: Which part of the precipitating water percolates into the soil and which is the rate of percolation? This question touches on the behaviour of partially saturated soil, which is experimentally and theoretically very challenging. The following article deals with this (Zhang and Li, 2021).

Besides the mechanical behaviour of soil, we should not forget that soil is a porous material. Fluids can circulate in its pores, in which all kinds of pollutants can spread. The low permeability implies a low percolation rate. The soil is thus a temporary barrier to contamination, which should often be controlled or inertialised. This is the subject of the next article by Liu et al. (2021).

Engineering science lives in the area of tension between theory and practice, whereby theory is the basis for scientific progress. As Truesdell and Noll (1965) pointed out, 'theory must be based on experience, but experiment comes after, rather than before, theory. Without theoretical concepts one would neither know what experiments to perform nor be able to interpret their outcome.' 
Environmental Geotechnics

Volume 8 Issue 5
Editorial: Interventions into soil can

amelliorate its properties

Kolymbas
Nowadays we experience 'plebiscience', a decline of science, the main reason of which is the pressure to publish and to survive in the midst of a flood of mediocrity. Nobody has the time needed to read and to think. A result of this policy can be seen in the field of soil mechanics, where increasing confusion spreads. For example extraordinarily complicated and incomprehensible constitutive laws have become the mainstream and this brings with it the germ of proliferation: confusing complexity undermines mastering and thus encourages the urge to conform to the mainstream. The flood of meaningless publications can only be contained by good science, that is science with commitment and enthusiasm to simplicity, comprehensibility and responsibility far from any conformism to established but incomprehensible concepts.

\section{REFERENCES}

Alnunu MZ and Nalbantoglu Z (2021) Performance of loose sand with different waste materials in stone columns in North Cyprus. Environmental Geotechnics 8(5): 318-323, https://doi.org/10.1680/ jenge. 18.00079
Chen JY, Chen IH and Su MB (2021) In situ debris-cement admixture testing in alpine wild creeks, Taiwan. Environmental Geotechnics 8(5): 309-317, https://doi.org/10.1680/jenge.18.00088.

Inazumi S, Shishido K and Soralump S (2021) Possibility of impervious coating for the geotechnical reuse of soil and solid waste. Environmental Geotechnics 8(5): 324-333, https://doi.org/10.1680/jenge.17.00097.

Kolymbas D (2021) Barodesy with a new concept for critical voidratio. Geotechnik, https://doi.org/10.1002/gete.202000037.

Liu F, Zhou WH, Yi S and Geng X (2021) Morphological and mineral features of nZVI-induced precipitation on quartz particles. Environmental Geotechnics 8(5): 357-364, https://doi.org/10.1680/ jenge. 18.00081 .

Miao L, Wang F, Ye W et al. (2021) Combined method limiting shrinkage-swelling behaviours of expansive soils in Huai'an, China. Environmental Geotechnics 8(5): 334-344, https://doi.org/10.1680/ jenge.18.00009.

Truesdell CA and Noll W (1965) The non-linear field theories of mechanics. In Encyclopedia of Physics, Vol. IIIc. Springer, Berlin, Germany, pp. 1-579.

Zhang J and Li J (2021) Coupling effect on shallow slope stability under infiltration. Environmental Geotechnics 8(5): 345-356, https://doi. org/10.1680/jenge.18.00100. 